\title{
Fitossociologia de remanescentes de floresta estacional decidual em Corumbá, Estado do Mato Grosso do Sul, Brasil
}

\author{
SUZANA MARIA SALIS ${ }^{1,5}$, MARTA PEREIRA DA SILVA², PATRÍCIA PÓVOA DE MATTOS ${ }^{3}$, \\ JOÃO S. VILA DA SILVA4, VALI JOANA POTT² e ARNILDO POTT ${ }^{2}$
}

(recebido: 28 de agosto de 2003; aceito: 22 de julho de 2004)

\begin{abstract}
Phytosociological study on deciduous forest remnants near Corumbá, Mato Grosso do Sul State, Brazil). A survey was made on four deciduous forest remnants in the town of Corumbá, State of Mato Grosso do Sul (19 $05^{\circ}-19^{\circ} 20^{\prime} \mathrm{S}^{\circ}$ and $\left.57^{\circ} 40^{\prime}-57^{\circ} 55^{\prime} \mathrm{W}\right)$, aiming to verify the floristic and structure variation of deciduous forest remnants in different relief and types of soils. The four remnants were sampled through the point quarter method. Three areas were sampled through 20 points and the fourth area was sampled through 50 points. All trees with circumference at breast height $\geq 9 \mathrm{~cm}$ were sampled. In the alluvial deciduous forest, 32 species were sampled, Attalea phalerata Mart. ex Spreng. (Arecaceae) and Aspidosperma australe Müll. Arg. (Apocynaceae) having the highest importance value indexes. In two areas of lowland deciduous forest 47 and 25 species were sampled, respectively; Sebastiania discolor (Spreng.) Müll. Arg. (Euphorbiaceae) and Phyllostylon rhamnoides (J. Poiss.) Taub. (Ulmaceae) being the most important in both. In the remnant of submontane deciduous forest 24 species were sampled, Acosmium cardenasii H.S. Irwin \& Arroyo (Fabaceae) outstanding as the main species. The richest family was Fabaceae with 16 species, followed by Euphorbiaceae with six species, and Apocynaceae, Rubiaceae and Sapindaceae with five species each. Both areas of lowland forests showed to be very similar in floristic composition as well as in structure. The alluvial forest presented the most distinct structure and floristic when compared to the other areas. These remnants of deciduous forests have peculiar structure and floristic composition, containing species of the Chaco and Caatinga Provinces that require extensive botanical and ecological studies.
\end{abstract}

Key words - calcareous soil, Central West Brazil, deciduous forest, floristic composition

RESUMO - (Fitossociologia de remanescentes de floresta estacional decidual em Corumbá, Estado do Mato Grosso do Sul,

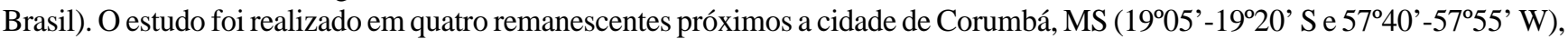
com o objetivo de verificar a variação da composição florística e estrutura da floresta decídua em diferentes relevos e tipos de solo. Quatro remanescentes foram amostrados pelo método de quadrantes. Três áreas foram amostradas com 20 pontos, e a quarta área foi amostrada com 50 pontos. Todas as árvores com circunferência à altura do peito $\geq 9 \mathrm{~cm}$ foram amostradas. Na floresta estacional decidual aluvial foram amostradas 32 espécies, sendo as de maior valor de importância Attalea phalerata Mart. ex Spreng. (Arecaceae) e Aspidosperma australe Müll. Arg. (Apocynaceae). Nas duas áreas de floresta estacional decidual de terras baixas, foram amostradas 47 e 25 espécies, respectivamente, sendo Sebastiania discolor (Spreng.) Müll. Arg. (Euphorbiaceae) e Phyllostylon rhamnoides (J. Poiss.) Taub. (Ulmaceae) as mais importantes em ambas. No remanescente de floresta estacional decidual submontana foram amostradas 24 espécies, sobressaindo-se Acosmium cardenasii H.S. Irwin \& Arroyo (Fabaceae) como a mais importante. A família mais rica nas áreas estudadas foi Fabaceae, com 16 espécies, seguida por Euphorbiaceae, com seis espécies, e por Apocynaceae, Rubiaceae e Sapindaceae, com três espécies cada. As duas áreas de florestas de terras baixas mostraram-se muito similares, tanto na composição florística, como na estrutura. A floresta aluvial apresentou composição florística e estrutura mais distintas das demais áreas. Estes remanescentes de florestas estacionais deciduais apresentaram estrutura e composição florística peculiares, com elementos do chaco e da caatinga, merecendo a intensificação de estudos botânicos e ecológicos.

Palavras-chave - Centro-Oeste brasileiro, composição florística, floresta decídua, solo calcário

\section{Introdução}

As formações vegetais decíduas ocorrem de maneira disjunta na América do Sul. São encontradas

1. Embrapa Pantanal, Caixa Postal 109, 79320-900 Corumbá, MS, Brasil.

2. Embrapa Gado de Corte, Caixa Postal 154, 79002-970 Campo Grande, MS, Brasil.

3. Embrapa Florestas, Caixa Postal 319, 83411-000 Colombo, PR, Brasil.

4. Embrapa Informática Agropecuária, Caixa Postal 6041, 13083-970 Campinas, SP, Brasil.

5. Autor para correspondência: smsalis@cpap.embrapa.br principalmente na região central e nordeste do Brasil, no noroeste da Argentina (Missiones) e no sudoeste da Bolívia, sendo consideradas por Prado \& Gibbs (1993) formações residuais de climas secos do Pleistoceno. A vegetação decídua dos morros adjacentes à cidade de Corumbá é mencionada como integrante do núcleo de Missiones (Prado \& Gibbs 1993).

As primeiras informações sobre composição e distribuição da flora dos arredores de Corumbá são encontradas nas publicações de Moore (1895), Hoehne (1923) e Malme (1905a, b, 1931), relatando a ocorrência 
de espécies para algumas famílias, como Leguminosae e Vochysiaceae. Em Brasil (1982), Mato Grosso do Sul (1989) e Pott et al. (2000) têm-se informações cartográficas recentes sobre a vegetação, com base em imagens de radar e satélite, trazendo estudo de mapeamento e zoneamento, porém com poucas informações sobre a composição florística e estrutura da vegetação decídua da morraria de Corumbá. Ratter et al. (1988) descrevem a composição florística e a estrutura da vegetação decídua de um morro calcário de Corumbá, relacionando-as com espécies xerófilas e calcífilas ocorrentes na caatinga nordestina. No entanto, mesmo com indicativos destas similaridades e afinidades, Pott et al. (1997) afirmam que a flora nos planaltos que circundam o Pantanal, na qual se inclui a região de morros de Corumbá, é ainda pouco conhecida por ser escassamente coletada e estudada.

As terras no entorno de Corumbá, regionalmente chamados de morros, são áreas que não inundam e, por isso, utilizadas como refúgio pelos animais silvestres e gado durante o período de cheia no Pantanal. Nos morros, a pecuária ocorre associada à pastagem cultivada sendo que, a partir de 1984, foram implantados vários assentamentos na região, aumentando muito a pressão de desmatamento sobre a vegetação natural remanescente na morraria (Spera et al. 1997). A vegetação destes remanescentes sofre, ainda, outras perturbações antrópicas como queimadas, retiradas clandestinas de madeira, ocupação para moradia e mineração (Valverde 1972, Juracy et al. 1999), que representam uma grande ameaça a biodiversidade da formação, por ser uma das poucas regiões do Estado do Mato Grosso do Sul com vegetação chaquenha (Prado et al. 1992).

Este trabalho teve por objetivo verificar a variação da composição florística e da estrutura em remanescentes de floresta decídua nos arredores da cidade de Corumbá, MS em diferentes relevos e tipos de solo, para subsidiar ações futuras de conservação e manejo sustentável dessas florestas.

\section{Material e métodos}

Os quatro remanescentes estudados estão na porção sudoeste da morraria de Corumbá, região rural não inundável

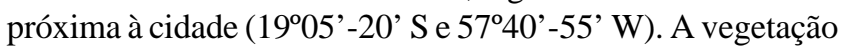
destes remanescentes, conhecida regionalmente como mata seca ou calcária, é classificada como Floresta Estacional Decidual (IBGE 1992), e apresenta mais de 50\% dos indivíduos decíduos no período de déficit hídrico. Esta formação apresenta três fitofisionomias distintas na região: Aluvial,
Terras Baixas e Submontana (IBGE 1992).

O clima da região é do tipo Awa, segundo a classificação de Köppen, ou seja, tropical de altitude, megatérmico (temperatura média do mês mais frio superior a $18^{\circ} \mathrm{C}$ ), com inverno seco e chuvas no verão (Soriano 1997). As médias anuais de precipitação e temperatura, no período de 1975-1996, foram $1.070 \mathrm{~mm} \mathrm{e} 25,1^{\circ} \mathrm{C}$, respectivamente. A maior precipitação média ocorreu em janeiro, com $191 \mathrm{~mm}$ e a menor, em julho, com $19 \mathrm{~mm}$, apresentando uma deficiência hídrica anual de $318 \mathrm{~mm}$. A temperatura máxima absoluta atinge $40{ }^{\circ} \mathrm{C}$ nos meses de outubro a janeiro, e as mínimas absolutas são próximas a $0^{\circ} \mathrm{C}$, nos meses de maio a agosto (Soriano 1997).

Os quatro remanescentes amostrados ocorrem em diferentes tipos solos (Spera et al. 1997, Embrapa 1999) e relevo, desde plano à suave ondulado, com altitude de $100 \mathrm{a}$ $150 \mathrm{~m}$ e declividade inferior a $2 \%$, e também de ondulado a montanhoso, com cotas altimétricas em torno de $300 \mathrm{~m}$ e declividade de $20 \%-40 \%$ (Spera et al. 1997). O primeiro remanescente, denominado Lagoa Jacadigo, com aproximadamente 100 ha, é uma floresta aluvial, às margens da lagoa Jacadigo, sobre Vertissolo Ebânico Carbonático chernossólico, textura argilosa, em relevo plano, com dique aluvial próximo a margem da lagoa (figura 1). O segundo remanescente, localizado no Morro Jacadigo, é uma floresta submontana com área de 800 ha sobre mancha de Cambissolo Háplico Ta Eutrófico, textura média/média pouco cascalhenta fase pedregosa, em relevo ondulado (com $20 \%$ a $40 \%$ de inclinação). $\mathrm{O}$ terceiro remanescente foi selecionado no Taquaral, com aproximadamente 3.400 ha, sendo uma floresta de terras baixas dentro de um assentamento, sobre Vertissolo Ebânico Carbonático chernossólico, textura argilosa, relevo plano. O quarto remanescente, Fronteira, com cerca de 25 ha, é uma floresta de terras baixas, na fronteira com a Bolívia, sobre Chernossolo Argilúvico Órtico abrúptico (= Brunizém avermelhado), textura média, associado com Vertissolo Ebânico Sódico, textura argilosa, em relevo plano. Atualmente, os dois últimos remanescentes são áreas de cultivo e pastagem, respectivamente.

A amostragem foi feita em 1992, utilizando o método de quadrantes (Brower \& Zar 1984), tomando-se 10 pontos em duas linhas distantes cerca de $300 \mathrm{~m}$. Os pontos foram iniciados a aproximadamente $5 \mathrm{~m}$ da borda da mata, distanciados $15 \mathrm{~m}$ entre si, totalizando 20 pontos amostrados em três das áreas estudadas, exceto na área do remanescente Taquaral onde foram levantados 50 pontos dispostos em três linhas (duas com 20 pontos e uma com 10). Foram incluídas árvores com CAP (circunferência à altura do peito) igual ou superior a nove centímetros e foi coletado material para identificação. As estimativas das alturas dos indivíduos amostrados foram utilizadas para a confecção de um diagrama, sendo representadas a amplitude e a mediana para as espécies com mais de três indivíduos. O material botânico coletado foi depositado no herbário da Embrapa Pantanal, (CPAP). A identificação foi realizada por comparação com material já 
existente no herbário CPAP, por consulta à literatura, à coleção do herbário de Edimburgo e a especialistas.

Os parâmetros fitossociológicos (freqüência, densidade relativa, dominância e índice sintético de importância), de acordo com Martins (1991), foram calculados com o programa Fitopac (Shepherd 1988). As distâncias médias entre indivíduos, densidades totais e absolutas, erro padrão e intervalo de confiança foram obtidos pelo programa Krebs (1998), com as fórmulas apresentadas por Krebs (1989).

A comparação florística entre os remanescentes de floresta decidual foi efetuada pelo índice de Jaccard, baseada na presença e ausência de espécies. A comparação da estrutura foi feita pelo índice de Czekanowski, baseada na densidade relativa das espécies (Pielou 1984). Para que a comparação fosse possível entre as quatro áreas, utilizou-se 20 pontos de quadrantes para o remanescente Taquaral, considerados os 10 primeiros pontos das duas primeiras linhas amostradas.

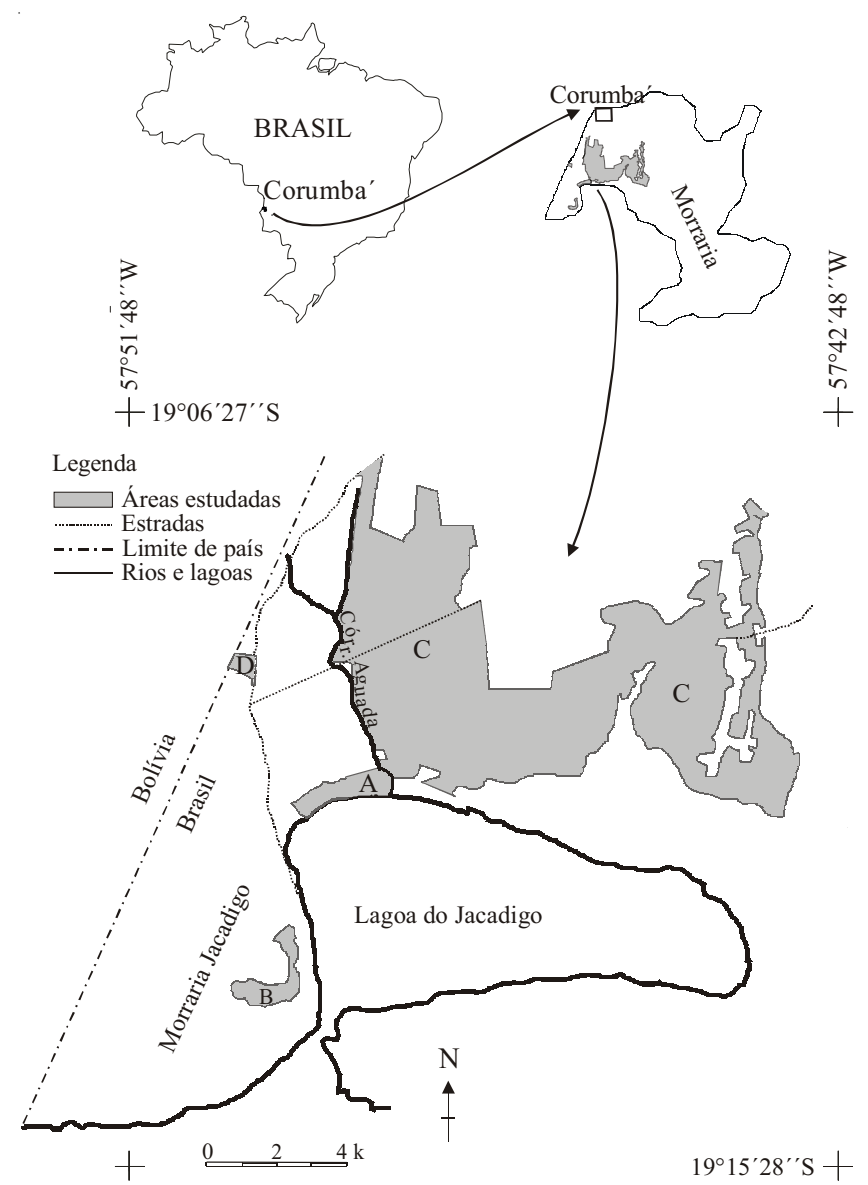

Figura 1. Localização dos remanescentes de Floresta Estacional Decidual Aluvial Jacadigo (A), Submontana Jacadigo (B), Terras Baixas Taquaral (C) e Terras Baixas Fronteira (D).

Figure 1. Remnants location in Jacadigo alluvial deciduous forest (A), Jacadigo submontane (B), Taquaral lowland (C) and Fronteira lowland (D).

\section{Resultados e Discussão}

No total, foram amostradas 79 espécies, distribuídas em 62 gêneros e 30 famílias (tabela 1), apresentadas em ordem alfabética de família, de acordo com Angiosperm Phylogeny Group (2003). A riqueza de espécies e famílias total está próxima a observada por Araújo et al. (1997) e Carvalho et al. (1999) em florestas decíduas em Uberlândia (66 espécies, 30 famílias) e em Santa Vitória (60 espécies, 30 famílias), em Minas Gerais, com a ressalva de que os critérios de inclusão e amostragem das árvores diferiram um pouco (CAP $\geq 5 \mathrm{~cm}$ e CAS $\geq 15,7 \mathrm{~cm}$, respectivamente). Entretanto, Pinard \& Hufman (1997) observaram uma riqueza maior, cerca de 140 espécies, em floresta decídua da Bolívia que consideram uma floresta diferente, por estar situada geograficamente na transição entre a vegetação da Amazônia, do Cerrado e do Chaco, mas que, segundo Prado \& Gibbs (1993), tem afinidade florística com a caatinga. Werneck et al. (2000) também obtiveram riqueza maior, 114 espécies, numa floresta decídua do Triângulo Mineiro, devido provavelmente à fase de sucessão que a área se encontra.

A família Fabaceae destacou-se como a mais rica, com sete espécies, em três remanescentes (Taquaral, Lagoa e Morro Jacadigo). Euphorbiaceae e Rubiaceae ocorreram com quatro espécies nos remanescentes Taquaral e Fronteira, respectivamente. Esses valores encontrados por família são próximos aos observados por Ratter et al. (1988) e Carvalho et al. (1999) em floresta decídua em Corumbá, MS e Santa Vitória, MG, respectivamente. Segundo Araújo et al. (1997) e Carvalho et al. (1999) as florestas decíduas apresentam uma menor riqueza de espécies lenhosas e a ocorrência de espécies com alta dominância, com um grupo de espécies típicas muito fiel, mencionadas por Ratter et al. (1988) como indicadoras de solos mesotróficos. Neste trabalho foram observadas seis dessas espécies indicadoras de solos mesotróficos que estão assinaladas na tabela 1 .

No remanescente Lagoa Jacadigo, foram encontradas 32 espécies (tabelas 1,2), onde a palmeira Attalea phalerata Mart. ex Spreng. foi uma das mais importantes e o principal componente do sub-bosque (figura 2). No entanto, cabe ressaltar que o valor da dominância absoluta (área basal) deste táxon está superestimado por causa da impossibilidade de se medir o perímetro do estipe excluindo-se as bainhas persistentes (tabela 2). Aspidosperma australe Müll. Arg., principal componente do dossel, destacou-se no remanescente, ocorrendo com grande número de 
Tabela 1. Espécies amostradas em quatro remanescentes de Floresta Estacional Decidual, Corumbá, MS, seus nomes populares, ocorrência nos remanescentes (1. Lagoa Jacadigo; 2. Morro Jacadigo; 3. Fronteira e 4. Taquaral), ocorrência em outras formações, segundo Scheinvar $(1985)^{1}$, Ratter et al. $(1988)^{2}$, Ramella \& Spichiger $(1989)^{3}$, Lorenzi $(1992)^{4}$, Killeen et al. $(1993)^{5}$, Prado \& Gibbs (1993) $)^{6}$, Pott \& Pott $(1994)^{7}$, Lorenzi $(1998)^{8}$, Mendonça et al. $(1998)^{9}$ Sales et al. $(1998)^{10}$, Missouri Botanical Garden $(2003)^{11}$ e número do coletor do exemplar depositado no herbário CPAP (A- Arnildo Pott, M- Marta P. Silva, S- Suzana M. Salis e V- Vali J. Pott), * espécies indicadoras de solos mesotróficos segundo Ratter et al. (1988), †espécies do Taquaral excluídas da comparação.

Table 1. Species sampled in four remnants of deciduous forest, Corumba, MS, common names, occurrence remnants (1. Lagoa Jacadigo; 2. Morro Jacadigo; 3. Fronteira e 4. Taquaral) occurrence in other forest formations, according to Scheinvar (1985) ${ }^{1}$, Ratter et al. $(1988)^{2}$, Ramella \& Spichiger $(1989)^{3}$, Lorenzi $(1992)^{4}$, Killeen et al. $(1993)^{5}$, Prado \& Gibbs $(1993)^{6}$, Pott \& Pott (1994) ${ }^{7}$, Lorenzi $(1998)^{8}$, Mendonça et al. $(1998)^{9}$ Sales et al. $(1998)^{10}$, Missouri Botanical Garden $(2003)^{11}$ and collect number of the exsiccate deposited in the CPAP herbarium (A- Arnildo Pott, M- Marta P. Silva, S- Suzana M. Salis e V- Vali J. Pott), * indicator species of mesotrophic soils according to Ratter et al. (1988), $\dagger$ Taquaral species excluded from comparison analyses.

\begin{tabular}{|c|c|c|c|c|}
\hline Família/Espécie & Nome popular & $\begin{array}{l}\text { Ocorrência } \\
\text { los remanescentes }\end{array}$ & $\begin{array}{l}\text { Ocorrência em outras } \\
\text { formações }\end{array}$ & $\begin{array}{l}\text { Número } \\
\text { coletor }\end{array}$ \\
\hline \multicolumn{5}{|l|}{ ACHATOCARPACEAE } \\
\hline Achatocarpus praecox Griseb. & & 1 & chaco $^{5}$ & S- 841 \\
\hline \multicolumn{5}{|l|}{ ANACARDIACEAE } \\
\hline $\begin{array}{l}\text { Astronium fraxinifolium Schott } \\
\text { ex Spreng. }{ }^{* \dagger}\end{array}$ & gonçalo & 4 & ampla $^{7}$ & A- 1415 \\
\hline Myracrodruon urundeuva Allemão* & aroeira & 4 & caatinga, cerradão, chaco ${ }^{2,3,6}$ & M-31 \\
\hline \multicolumn{5}{|l|}{ ANNONACEAE } \\
\hline Rollinia emarginata Schltdl. $\dagger$ & & $1,3,4$ & chaco $^{7}$, mata ciliar ${ }^{9}$ & A- 6967 \\
\hline \multicolumn{5}{|l|}{ APOCYNACEAE } \\
\hline Aspidosperma australe Müll.Arg. & guatambu & 1 & chaco $^{7}$ & A- 2808 \\
\hline Aspidosperma parvifolium A.DC. & guatambu & 2,3 & ampla $^{4}$ & V-2556 \\
\hline Aspidosperma pyrifolium Mart. & & $2,3,4$ & caatinga, chaco ${ }^{2,6}$ & S- 401 \\
\hline Aspidosperma quebracho-blanco Schltdl. $\dagger$ & quebracho-branco & 4 & $\operatorname{chaco}^{7}$ & A- 6960 \\
\hline Aspidosperma subincanum Mart.* & & 2 & ampla, caatinga ${ }^{2}$ & A- 7171 \\
\hline \multicolumn{5}{|l|}{ ARECACEAE } \\
\hline Acrocomia aculeata (Jacq.) Lodd. ex Mart.* & * bocaiúva & 1 & $\mathrm{ampla}^{7}$ & \\
\hline Attalea phalerata Mart. ex Spreng. & acuri & 1 & $\mathrm{ampla}^{7}$ & \\
\hline $\begin{array}{l}\text { Copernicia alba Morong ex Morong \& } \\
\text { Britton }\end{array}$ & carandá & 1 & chaco $^{7}$ & A- 6961 \\
\hline \multicolumn{5}{|l|}{ BIGNONIACEAE } \\
\hline Tabebuia heptaphylla (Vell.) Toledo & piúva & 3,4 & ampla, chaco ${ }^{7}$ & \\
\hline \multicolumn{5}{|l|}{ BORAGINACEAE } \\
\hline Cordia glabrata (Mart.) A. DC.* & louro & 4 & caatinga, chaco ${ }^{2,7}$ & M- 33 \\
\hline Saccellium brasiliense I.M. Johnston & & 4 & chaco $^{8}$ & M- 84 \\
\hline \multicolumn{5}{|l|}{ BRASSICACEAE } \\
\hline Capparis retusa Griseb. & & $1,2,3,4$ & chaco $^{7}$ & V-758 \\
\hline Capparis speciosa Griseb. & mangaba-brava & 4 & chaco $^{7}$ & A- 4449 \\
\hline \multicolumn{5}{|l|}{ CACTACEAE } \\
\hline $\begin{array}{l}\text { Aporocactus flagelliformis (L.) Lem. } \\
\text { CANNABACEAE }\end{array}$ & & 3 & México $^{1}$ & V-431 \\
\hline $\begin{array}{l}\text { Celtis pubescens Spreng. } \\
\text { COMBRETACEAE }\end{array}$ & taleira & 1,3 & ampla, caatinga, chaco ${ }^{6,7}$ & A- 3787 \\
\hline $\begin{array}{l}\text { Combretum leprosum Mart. } \\
\text { ERYTHROXYLACEAE }\end{array}$ & carne-de-vaca & 1 & caatinga, chaco ${ }^{2,6}$ & M-97 \\
\hline $\begin{array}{l}\text { Erythroxylum patentissimum O.E. Schulz } \dagger \\
\text { EUPHORBIACEAE }\end{array}$ & & 4 & chaco & A- 5282 \\
\hline $\begin{array}{l}\text { Adelia spinosa (Chodat \& Hassl.) } \\
\text { Pax \& Hoffm. }\end{array}$ & laranjinha-branca & 1,4 & chaco & M- 77 \\
\hline
\end{tabular}


continuação

\begin{tabular}{|c|c|c|c|c|}
\hline Família/Espécie & Nome popular & $\begin{array}{c}\text { Ocorrência } \\
\text { nos remanescentes }\end{array}$ & $\begin{array}{l}\text { Ocorrência em outras } \\
\text { formações }\end{array}$ & $\begin{array}{l}\text { Número } \\
\text { coletor }\end{array}$ \\
\hline Cnidoscolus cnicodendron Griseb. & cansanção & 1,2 & caatinga, chaco ${ }^{11}$ & V-912 \\
\hline Croton sp. $\dagger$ & & 4 & & S- 1097 \\
\hline Sapium sp. & & 2 & & S- 1100 \\
\hline cf. Savia sp. & & 3,4 & & S- 1104 \\
\hline Sebastiania discolor (Spreng.) Müll. Arg. & & 3,4 & chaco & S- 1105 \\
\hline \multicolumn{5}{|l|}{ FABACEAE } \\
\hline Acacia paniculata Willd. $\dagger$ & espinheiro & 2,4 & ampla, chaco ${ }^{7}$ & M-42 \\
\hline Acacia polyphylla DC. & & 2 & ampla $^{4}$ & S- 1116 \\
\hline Acosmium cardenasii H.S. Irwin \& Arroyo & & $2,3,4$ & savana (Bolívia) ${ }^{5}$ & S-769 \\
\hline $\begin{array}{l}\text { Albizia niopoides (Spruce ex Benth.) } \\
\text { Burkart }\end{array}$ & mulateira & 1,2 & $\operatorname{ampla}^{7}$ & V-990 \\
\hline $\begin{array}{l}\text { Anadenanthera colubrina (Vell.) Brenan } \\
\text { var. cebil (Griseb.) Altschul* }\end{array}$ & angico & 4 & caatinga, cerradão, chaco $^{6}$ & S-758 \\
\hline Bauhinia leptantha Malme & pé-de-boi & 2,4 & sem informações & V-2502 \\
\hline Bauhinia pentandra (Bong.) Vogel ex Steud. & d. unha-de-vaca & 1,2 & ampla $^{7}$ & S-768 \\
\hline Bauhinia rufa (Bong.) Steud. & pé-de-boi & 3 & caatinga $^{7}$, cerrado $^{9}$ & V-2553 \\
\hline Goldmania paraguensis (Benth.) Brenan & pau-alho & 1 & $\operatorname{chaco}^{7}$ & $\mathrm{~V}-2241$ \\
\hline Lonchocarpus cf. sericeus (Poir.) Kunth ex DC. & C. falso-ingá & 1 & caatinga $^{7}$ & \\
\hline Machaerium cf. stipitatum (DC.) Vogel $\dagger$ & sapuva & 4 & ampla $^{4}$ & S- 1121 \\
\hline Piptadenia stipulacea (Benth.) Ducke $\dagger$ & & 4 & caatinga $^{10}$ & A- 4858 \\
\hline Piptadenia viridiflora (Kunth) Benth. & espinheiro & 2 & caatinga, floresta (Bolívia) $)^{5,6}$ & S- 1117 \\
\hline Pterogyne nitens Tul. & bálsamo & 1 & ampla $^{4}$, caatinga ${ }^{4,6}$, chaco $^{6}$ & S-789 \\
\hline Fabaceae 1 & & 1 & & S- 1106 \\
\hline Fabaceae 2 & & $1,3,4$ & & S- 1110 \\
\hline \multicolumn{5}{|l|}{ MALVACEAE } \\
\hline Ceiba pubiflora (A.St.-Hil.) K. Schum. $\dagger$ & barriguda & 2,4 & $\operatorname{chaco}(\text { Bolívia })^{5}$ & S- 643 \\
\hline $\begin{array}{l}\text { Helicteres lhotzkyana (Schott \& Endl.) } \\
\text { K. Schum. } \dagger\end{array}$ & rosquinha & 1,4 & ampla $^{7}$ & M- 95 \\
\hline Luehea paniculata Mart. & açoita-cavalo & 2 & ampla $^{7}$ & S- 1109 \\
\hline \multicolumn{5}{|l|}{ MELIACEAE } \\
\hline cf. Trichilia sp. & & 4 & & S- 1098 \\
\hline \multicolumn{5}{|l|}{ MORACEAE } \\
\hline Fícus sp. & figueira & 1 & & S- 1099 \\
\hline Maclura tinctoria (L.) D. Don ex Steud. & taiúva & 3,4 & ampla, caatinga ${ }^{2,7}$ & S- 1117 \\
\hline \multicolumn{5}{|l|}{ MYRTACEAE } \\
\hline Plinia cauliflora (DC.) Kausel & jabuticaba & 1,4 & Bolívia $^{11}$ & S- 1101 \\
\hline Myrtaceae $1 \dagger$ & & 4 & & S- 1102 \\
\hline Myrtaceae $2 \dagger$ & & 3,4 & & S- 1103 \\
\hline \multicolumn{5}{|l|}{ NYCTAGINACEAE } \\
\hline Neea subpubescens Heimerl† & & 1,4 & floresta (Bolívia) ${ }^{5}$ & S- 1111 \\
\hline Pisonia cf. ambigua Heimerl & & 2 & savana (Bolívia) $)^{5,7}$ & S- 1112 \\
\hline Reichenbachia paraguayensis (Parodi) & & $1,2,4$ & $\operatorname{chaco}^{5}$ & V-2551 \\
\hline Dugand \& Daniel & & & & \\
\hline \multicolumn{5}{|l|}{ PIPERACEAE } \\
\hline Piper angustifolium Lam. & pimenta-do-mato & 1 & ampla $^{7}$ & S- 1122 \\
\hline \multicolumn{5}{|l|}{ POLYGONACEAE } \\
\hline Coccoloba cujabensis Wedd. & canjiquinha & 2,4 & savana (Bolívia) ${ }^{5,7}$ & M- 42 \\
\hline Coccoloba rigida Meisn. & canjiquinha & 4 & $\operatorname{chaco}^{7}$ & A- 5290 \\
\hline Coccoloba sp. $\dagger$ & & 3,4 & & S- 1108 \\
\hline \multicolumn{5}{|l|}{ RHAMNACEAE } \\
\hline Zizyphus oblongifolius S. Moore $\dagger$ & olho-de-boi & $1,3,4$ & $\operatorname{chaco}^{6}$ & $\begin{array}{l}\text { A- } 2792 \\
\text { continua }\end{array}$ \\
\hline
\end{tabular}




\begin{tabular}{|c|c|c|c|c|}
\hline Família/Espécie & Nome popular & $\begin{array}{c}\text { Ocorrência } \\
\text { nos remanescentes }\end{array}$ & $\begin{array}{l}\text { Ocorrência em outras } \\
\text { formações }\end{array}$ & $\begin{array}{l}\text { Número } \\
\text { coletor }\end{array}$ \\
\hline \multicolumn{5}{|l|}{ RUBIACEAE } \\
\hline Calycophyllum multiflorum Griseb. $\dagger$ & castelo & 3,4 & $\operatorname{chaco}^{3,6}$ & S- 1119 \\
\hline Chomelia obtusa Cham. \& Schltdl. & taleira & 1,3 & ampla $^{7}$ & S-792 \\
\hline Coutarea hexandra (Jacq.) K. Schum. & & 3,4 & ampla $^{5}$, caatinga ${ }^{6}$ & M- 102 \\
\hline Randia armata (Sw.) DC. & unha-de-gato & $2,3,4$ & ampla $^{7}$ & S-771 \\
\hline Simira corumbensis (Standl.) Steyerm. & & 2 & sem informações & M- 32 \\
\hline \multicolumn{5}{|l|}{ RUTACEAE } \\
\hline Helietta puberula R.E. Fries & & $2,3,4$ & Bolívia $^{11}$ & V-2552 \\
\hline Zanthoxylum cf. gardneri Engl. & & 4 & caatinga $^{11}$ & \\
\hline \multicolumn{5}{|l|}{ SALICACEAE } \\
\hline cf. Abatia sp. & & 2 & & \\
\hline Casearia decandra Jacq $\dagger^{\dagger}$ & pururuca & 3,4 & ampla $^{7}$ & A- 5292 \\
\hline Flacourtiaceae & & 4 & & S- 1107 \\
\hline \multicolumn{5}{|l|}{ SAPINDACEAE } \\
\hline Allophylus edulis (A.St.-Hil. et al.) Radlk. & & $1,2,3,4$ & ampla $^{4}$ & S- 1120 \\
\hline Allophylus pauciflorus Radlk. & & 3 & $\operatorname{ampla}^{5}$ & V-2255 \\
\hline Diplokeleba floribunda N.E. Brown $\dagger$ & canela-de-cotia & 3,4 & chaco $^{6}$ & A- 5299 \\
\hline Melicoccus lepidopetala Radlk. & água-pomba & 1 & chaco $^{7}$ & S- 802 \\
\hline Sapindus saponaria $\mathrm{L}$. & saboneteira & 1,4 & ampla $^{7}$ & A- 7773 \\
\hline \multicolumn{5}{|l|}{ SAPOTACEAE } \\
\hline $\begin{array}{l}\text { Sideroxylon obtusifolium (Humb. ex } \\
\text { Roem. \& Schult.) T.D. Penn. }\end{array}$ & laranjinha & 1,4 & chaco, caatinga $a^{5,6}$ & M- 100 \\
\hline \multicolumn{5}{|l|}{ ULMACEAE } \\
\hline Phyllostylon rhamnoides (J. Poiss.) Taub. & & $1,2,3,4$ & chaco $^{5}$ & M- 75 \\
\hline \multicolumn{5}{|l|}{ URTICACEAE } \\
\hline Cecropia pachystachya Trécul & embaúba & 1 & ampla $^{7}$ & \\
\hline \multicolumn{5}{|l|}{ VERBENACEAE } \\
\hline Aloysia virgata (Ruiz \& Pav.) A. Juss. & & 1 & $\mathrm{ampla}^{7}$ & M- 82 \\
\hline
\end{tabular}

indivíduos. Este remanescente apresentou a menor similaridade florística e estrutural em relação aos demais, sendo o único onde foram observadas três espécies de palmeiras, duas das quais ocorreram com vários indivíduos: Attalea phalerata, frequiente em locais bem drenado e com disponibilidade de cálcio (Pott \& Pott 1994) e Copernicia alba Morong ex Morong \& Britton, típica da formação chaquenha, comum em áreas alagáveis, indicadora de solos alcalinos ou salinos (Pott \& Pott 1994).

No Morro Jacadigo foram amostradas 24 espécies (tabela 1 e 3), onde se destacaram Acosmium cardenasii H.S Irwin \& Arroyo, como principal componente do dossel, Albizia niopoides (Spruce ex Benth.) Burkart, como emergente, e Capparis retusa Griseb., como principal espécie do sub-bosque (figura 2). Essa mata apresentou número de espécies e densidade total de árvores (tabela 7) semelhante ao encontrado por Ratter et al. (1988) usando metodologia semelhante com amostragem em 25 pontos e inclusão de árvores com PAP $\geq 10 \mathrm{~cm}$, numa floresta decídua de morro em Corumbá (1959' S e 56 39' W), sendo relatada a presença de 29 espécies e 1188 árvores por hectare. No entanto, a composição florística e as espécies dominantes das duas matas submontanas são muito diferentes, possivelmente devido aos diferentes tipos de solo.

Na floresta decídua do Morro Jacadigo foram observados indivíduos de grande porte de Cnidosculus cnicodendron Griseb., com $28 \mathrm{~cm}$ de diâmetro e até $12 \mathrm{~m}$ de altura. Pott e Pott (1986) consideram esta espécie como pioneira, pois apresenta capacidade de colonização e regeneração em áreas sujeitas a perturbações recorrentes, como margens de estradas, onde geralmente é encontrada com porte arbustivo. Lorenzi (1998) menciona também outras duas espécies 
Tabela 2. Espécies amostradas no remanescente Lagoa Jacadigo, em Floresta Estacional Decidual Aluvial, às margens da lagoa Jacadigo, Corumbá, MS, e seus parâmetros fitossociológicos, em ordem decrescente de valor de importância (VI). N = número de indivíduos amostrados; $\mathrm{FA}=$ freqüência absoluta $(\%) ; \mathrm{DA}=$ densidade absoluta (indivíduos.ha ${ }^{-1}$ ); $\mathrm{DR}=$ densidade relativa $(\%) ;$ DoR = dominância relativa $(\%)$.

Table 2. Sampled species of Lagoa Jacadigo remnants, in alluvial deciduous forest, by Jacadigo shallow lake margin, Corumba, MS, and its phytosociologics parameters, in decreasing order of importance value $(\mathrm{VI})$. N = number of sampled individuals; $\mathrm{FA}=$ absolute frequency $(\%) ; \mathrm{DA}=$ absolute density (individuous.ha $\left.{ }^{-1}\right) ; \mathrm{DR}=$ relative density $(\%)$; DoR $=$ relative dominance $(\%)$.

\begin{tabular}{|c|c|c|c|c|c|c|}
\hline Espécie & $\mathrm{N}$ & FA & DA & $\mathrm{DR}$ & DoR & VI \\
\hline Attalea phalerata & 9 & 40 & 114,20 & 11,25 & 70,16 & 92,37 \\
\hline Aspidosperma australe & 10 & 35 & 127,48 & 12,50 & 9,78 & 31,87 \\
\hline Copernicia Alba & 4 & 20 & 50,88 & 5,00 & 2,85 & 13,33 \\
\hline Pterogyne nitens & 4 & 15 & 50,88 & 5,00 & 3,12 & 12,23 \\
\hline Chomelia obtusa & 5 & 20 & 63,60 & 6,25 & 0,36 & 12,09 \\
\hline Achatocarpus praecox & 4 & 20 & 50,88 & 5,00 & 0,81 & 11,29 \\
\hline Cnidosculus cnicodendron & 4 & 20 & 50,88 & 5,00 & 0,52 & 11,00 \\
\hline Sideroxylon obtusifolium & 3 & 15 & 38,16 & 3,75 & 2,41 & 10,27 \\
\hline Zizyphus oblongifolius & 3 & 15 & 38,16 & 3,75 & 0,53 & 8,39 \\
\hline Capparis retusa & 3 & 15 & 38,16 & 3,75 & 0,15 & 8,01 \\
\hline Rollinia emarginata & 3 & 15 & 38,16 & 3,75 & 0,07 & 7,93 \\
\hline Ficus sp. & 2 & 10 & 25,44 & 2,50 & 2,20 & 7,44 \\
\hline Neea subpubescens & 2 & 10 & 25,44 & 2,50 & 0,53 & 5,77 \\
\hline Celtis pubescens & 2 & 10 & 25,44 & 2,50 & 0,46 & 5,70 \\
\hline Phyllostylon rhamnoides & 2 & 10 & 25,44 & 2,50 & 0,26 & 5,50 \\
\hline Adelia spinos & 2 & 10 & 25,44 & 2,50 & 0,18 & 5,42 \\
\hline Aloysia virgata & 2 & 10 & 25,44 & 2,50 & 0,16 & 5,40 \\
\hline Lonchocarpus cf. sericeus & 1 & 5 & 12,72 & 2,50 & 1,78 & 4,40 \\
\hline Sapindus saponaria & 1 & 5 & 12,72 & 1,25 & 1,55 & 4,17 \\
\hline Allophylus edulis & 2 & 5 & 25,44 & 1,25 & 0,10 & 3,97 \\
\hline Acrocomia aculeata & 1 & 5 & 12,72 & 2,50 & 0,72 & 3,33 \\
\hline Melicoccus lepidopetala & 1 & 5 & 12,72 & 1,25 & 0,26 & 2,88 \\
\hline Helicteres lhotzkyana & 1 & 5 & 12,72 & 1,25 & 0,22 & 2,84 \\
\hline Bauhinia pentandra & 1 & 5 & 12,72 & 1,25 & 0,16 & 2,78 \\
\hline Cecropia pachystachya & 1 & 5 & 12,72 & 1,25 & 0,15 & 2,77 \\
\hline Reichenbachia paraguayensis & 1 & 5 & 12,72 & 1,25 & 0,10 & 2,72 \\
\hline Plinia cauliflora & 1 & 5 & 12,72 & 1,25 & 0,10 & 2,72 \\
\hline Fabaceae 2 & 1 & 5 & 12,72 & 1,25 & 0,09 & 2,71 \\
\hline Goldmania paraguensis & 1 & 5 & 12,72 & 1,25 & 0,08 & 2,70 \\
\hline Albizia niopoides & 1 & 5 & 12,72 & 1,25 & 0,08 & 2,70 \\
\hline Piper angustifolium & 1 & 5 & 12,72 & 1,25 & 0,03 & 2,65 \\
\hline Combretum leprosum & 1 & 5 & 12,72 & 1,25 & 0,02 & 2,64 \\
\hline
\end{tabular}

do mesmo gênero como pioneiras, apresentando madeira leve e crescimento rápido, ambas ocorrentes na região da caatinga nordestina. Assim, a presença de C. cnicodendron, com porte arbóreo sugere que este trecho da mata submontana do Jacadigo tenha sofrido perturbação (remoção ou queda natural de árvores) há vários anos.

Nos dois remanescentes de Terras Baixas (Taquaral e Fronteira) foram amostrados 47 e 25 espécies, respectivamente, sendo Sebastiania discolor (Spreng.) Müll.Arg. e Phyllostylon rhamnoides (J. Poiss.) Taub. (tabelas 1, 4, 5), os principais componentes da estrutura vertical da mata (figura 2). Estes remanescentes apresentam dois estratos muito evidentes, um sub-bosque com indivíduos entre 3 e $6 \mathrm{~m}$ de altura, composto principalmente por S. discolor, arvoreta com tronco muito ramificado, e um dossel com 7 a 12 m, composto por P. rhamnoides. Na mata do 

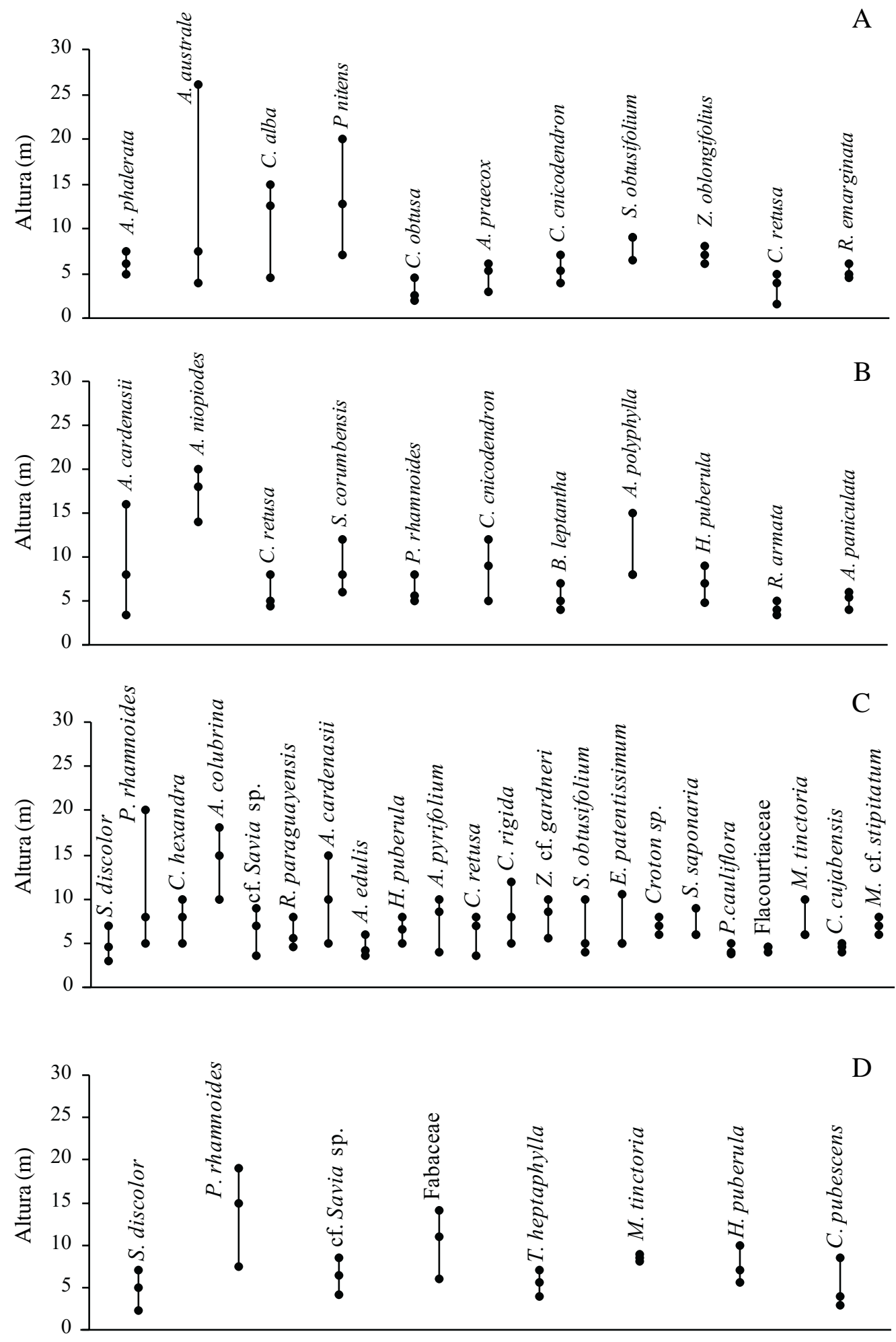

Espécies

Figura 2. Diagrama de estratificação vertical das espécies amostradas com mais de três indivíduos nos remanescentes de Floresta Estacional Decidual Aluvial Jacadigo (A), Submontana Jacadigo (B), Terras Baixas Taquaral (C) e Terras Baixas Fronteira (D). Cada traço é limitado pela amplitude das alturas, sendo o ponto sobre cada linha a mediana da espécie.

Figure 2. Vertical stratification diagram from sampled species with more than tree individuals in remnants of Jacadigo alluvial deciduous forest (A), Jacadigo submontane (B), Taquaral lowland (C) and Fronteira lowland (D). Ranges of heights were limited by each mark, considering the dot over each line the species median. 
Tabela 3. Espécies amostradas no remanescente Morro Jacadigo, em Floresta Estacional Decidual Submontana, no morro Jacadigo, Corumbá, MS, e seus parâmetros fitossociológicos, em ordem decrescente de valor de importância (VI). N = número de indivíduos amostrados; $\mathrm{FA}=$ freqüência absoluta $(\%) ; \mathrm{DA}=$ densidade absoluta (indivíduos.ha ${ }^{-1}$ ); $\mathrm{DR}=$ densidade relativa $(\%) ;$ DoR = dominância relativa $(\%)$.

Table 3. Sampled species of Morro Jacadigo remnants, in submontane deciduous forest, by Jacadigo hill, Corumba, MS, and its phytosociologics parameters, in decreasing order of importance value (VI). $\mathrm{N}=$ number of sampled individuals; FA = absolute frequency $(\%) ; \mathrm{DA}=$ Absolute density (individuous.ha $\left.{ }^{-1}\right) ; \mathrm{DR}=$ relative density $(\%)$; DoR = relative dominance $(\%)$.

\begin{tabular}{lrrrrrr}
\hline Espécie & N & FA & DA & DR & DoR & VI \\
\hline Acosmium cardenasii & 19 & 60 & 321,36 & 23,75 & 18,46 & 59,85 \\
Albizia niopoides & 3 & 15 & 50,74 & 3,75 & 31,74 & 39,90 \\
Ceiba pubiflora & 2 & 10 & 33,83 & 2,80 & 20,70 & 26,14 \\
Capparis retusa & 7 & 30 & 118,39 & 8,75 & 3,92 & 21,50 \\
Simira corumbensis & 5 & 25 & 84,57 & 6,25 & 4,31 & 17,91 \\
Phyllostylon rhamnoides & 6 & 25 & 101,48 & 7,50 & 1,83 & 16,69 \\
Cnidosculus cnicodendron & 4 & 20 & 67,65 & 5,00 & 4,95 & 15,83 \\
Bauhinia leptantha & 5 & 25 & 84,57 & 6,25 & 0,55 & 14,15 \\
Acacia polyphylla & 3 & 15 & 50,74 & 3,75 & 4,84 & 13,00 \\
Helietta puberula & 4 & 20 & 67,65 & 5,00 & 1,67 & 11,08 \\
Randia armata & 4 & 10 & 67,65 & 5,00 & 0,17 & 11,05 \\
Acacia paniculata & 3 & 10 & 50,74 & 3,75 & 0,33 & 7,02 \\
Sapium sp. & 2 & 10 & 33,83 & 2,50 & 1,47 & 6,91 \\
Reichenbachia paraguayensis & 2 & 10 & 33,83 & 2,50 & 0,48 & 5,92 \\
Aspidosperma pyrifolium & 2 & 10 & 33,83 & 2,50 & 0,33 & 4,30 \\
Luehea paniculata & 1 & 5 & 16,91 & 1,25 & 1,27 & 3,99 \\
Allophylus edulis & 1 & 5 & 16,91 & 1,25 & 1,15 & 3,87 \\
Neea subpubescens & 1 & 5 & 16,91 & 1,25 & 0,76 & 3,48 \\
Aspidosperma subincanum & 1 & 5 & 16,91 & 1,25 & 0,52 & 3,24 \\
Coccoloba cujabensis & 1 & 5 & 16,91 & 1,25 & 0,24 & 2,96 \\
cf. Abatia sp. & 1 & 5 & 16,91 & 1,25 & 0,15 & 2,87 \\
Aspidosperma parvifolium & 1 & 5 & 16,91 & 1,25 & 0,08 & 2,80 \\
Piptadenia viridiflora & 1 & 5 & 16,91 & 1,25 & 0,05 & 2,77 \\
Bauhinia pentandra & 1 & 5 & 16,91 & 1,25 & 0,03 & 2,75 \\
\hline
\end{tabular}

Taquaral aparece ainda, Coutarea hexandra (Jacq.) K. Schum., compondo o dossel, e Anadenanthera colubrina (Vell.) Brenan var. cebil (Griseb.) Altschul como emergente, com até $18 \mathrm{~m}$ de altura. No remanescente Fronteira não foram observados indivíduos emergentes.

Os remanescentes Fronteira e Taquaral foram os remanescentes mais similares, em torno de 30 e 50\%, nas comparações florística e de abundância de espécies, respectivamente (tabela 6). Ambos os remanescentes ocorrem no mesmo tipo de relevo, com o mesmo tipo de formação vegetal (Floresta Estacional Decidual de Terras Baixas) e, apesar de apresentarem os solos predominantes diferentes, a amostragem de vegetação do remanescente Fronteira pode ter sido feita sobre uma mancha de Vertissolo Ebânico Sódico, solo que aparece associado ao Chernossolo Argilúvico Órtico, que não é muito distinto química e fisicamente do Vertissolo Ebânico Carbonático da área do Taquaral. Isto poderia explicar a maior semelhança entre as duas matas. No remanescente Fronteira foi notada a ausência de indivíduos de Anadenanthera colubrina (Vell.) Brenan var. cebil (Griseb.) Altschul e Myracrodruon urundeuva Allemão, espécies típicas e muito freqüentes neste tipo de formação (Ratter et al. 1988, Prado \& Gibbs 1993, Pott et al. 1997, Oliveira Filho et al. 1998 e Salis et al. 1999), sugerindo o corte seletivo de madeira, pois são muito utilizadas na atividade pecuária da região (Pott \& Pott 1994).

No remanescente Fronteira, para as espécies amostradas com apenas um indivíduo, foram observados elevados valores de densidades absolutas (37 indivíduos.ha- $\mathrm{a}^{-1}$ ). Este valor se deve a uma característica do método de quadrantes utilizado para a 
Tabela 4. Espécies amostradas no remanescente Taquaral, em Floresta Estacional Decidual de Terras Baixas, no assentamento Taquaral, Corumbá, MS, e seus parâmetros fitossociológicos, em ordem decrescente de valor de importância (VI). N = número de indivíduos amostrados; FA = freqüência absoluta (\%); DA = densidade absoluta (indivíduos.ha $\left.{ }^{-1}\right) ; \mathrm{DR}=$ densidade relativa (\%); DoR = dominância relativa $(\%)$.

Table 4. Sampled species of Taquaral remnants, in lowland deciduous forest, in Taquaral community, Corumba, MS, and its phytosociologics parameters, in decreasing order of importance value $(\mathrm{VI}) . \mathrm{N}=$ number of sampled individuals; $\mathrm{FA}=$ absolute frequency (\%); DA = Absolute density (individuous.ha $\left.{ }^{-1}\right) ; \mathrm{DR}=$ relative density $(\%)$; DoR = relative dominance $(\%)$.

\begin{tabular}{|c|c|c|c|c|c|c|}
\hline Espécie & $\mathrm{N}$ & FA & DA & $\mathrm{DR}$ & DoR & VI \\
\hline Sebastiania discolor & 64 & 50 & 1035,31 & 32,00 & 8,94 & 58,42 \\
\hline Phyllostylon rhamnoides & 7 & 12 & 113,24 & 3,50 & 21,13 & 28,83 \\
\hline Coutarea hexandra & 11 & 16 & 177,94 & 5,50 & 6,03 & 17,12 \\
\hline Anadenanthera colubrina var. cebil & 5 & 10 & 80,88 & 2,50 & 8,64 & 14,63 \\
\hline Aspidosperma quebracho-blanco & 1 & 2 & 16,17 & 0,50 & 11,82 & 13,02 \\
\hline cf. Savia sp. & 10 & 14 & 161,77 & 5,00 & 1,30 & 11,20 \\
\hline Reichenbachia paraguayensis & 8 & 12 & 129,41 & 4,00 & 1,95 & 10,15 \\
\hline Acosmium cardenasii & 5 & 10 & 80,88 & 2,50 & 3,83 & 9,83 \\
\hline Allophylus edulis & 8 & 12 & 129,41 & 4,00 & 1,07 & 9,27 \\
\hline Ceiba pubiflora & 1 & 2 & 16,17 & 0,50 & 7,23 & 8,43 \\
\hline Helietta puberula & 5 & 10 & 80,88 & 2,50 & 1,11 & 7,11 \\
\hline Aspidosperma pyrifolium & 6 & 8 & 97,06 & 3,00 & 1,02 & 6,82 \\
\hline Capparis retusa & 5 & 8 & 80,88 & 2,50 & 0,78 & 6,08 \\
\hline Myracrodruon urundeuva & 2 & 4 & 32,35 & 1,00 & 3,62 & 6,02 \\
\hline Coccoloba rigida & 3 & 6 & 48,53 & 1,50 & 2,30 & 5,90 \\
\hline Adelia spinosa & 2 & 4 & 32,35 & 1,00 & 2,82 & 5,22 \\
\hline Zanthoxylum cf. gardneri & 3 & 6 & 48,53 & 1,50 & 1,33 & 4,92 \\
\hline Rollinia emarginata & 2 & 4 & 32,35 & 1,00 & 1,98 & 4,38 \\
\hline Sideroxylon obtusifolium & 3 & 6 & 48,53 & 1,50 & 0,65 & 4,25 \\
\hline Fabaceae 2 & 2 & 4 & 32,35 & 1,00 & 1,80 & 4,20 \\
\hline Erythroxylum patentissimum & 3 & 6 & 48,53 & 1,50 & 0,39 & 3,98 \\
\hline Croton sp. & 3 & 6 & 48,53 & 1,50 & 0,33 & 3,93 \\
\hline Saccellium brasiense & 1 & 2 & 16,17 & 0,50 & 2,73 & 3,93 \\
\hline Sapindus saponaria & 3 & 6 & 48,53 & 1,50 & 0,31 & 3,91 \\
\hline Plinia cauliflora & 3 & 6 & 48,53 & 1,50 & 0,27 & 3,87 \\
\hline Flacourtiaceae & 3 & 6 & 48,53 & 1,50 & 0,17 & 3,77 \\
\hline Zzizyphus oblongifolius & 2 & 2 & 32,35 & 1,00 & 1,95 & 3,65 \\
\hline Maclura tinctoria & 3 & 4 & 48,53 & 1,50 & 0,70 & 3,60 \\
\hline Machaerium cf. stipitatum & 3 & 4 & 48,53 & 1,50 & 0,40 & 3,30 \\
\hline Coccoloba cujabensis & 3 & 4 & 48,53 & 1,50 & 0,30 & 3,20 \\
\hline Capparis speciosa & 2 & 4 & 32,35 & 1,00 & 0,39 & 2,79 \\
\hline cf. Trichilia sp. & 2 & 4 & 32,35 & 1,00 & 0,38 & 2,78 \\
\hline Myrtaceae 2 & 2 & 4 & 32,35 & 1,00 & 0,14 & 2,54 \\
\hline Calycophyllum multiflorum & 1 & 2 & 16,17 & 0,50 & 0,38 & 1,58 \\
\hline Cordia glabrata & 1 & 2 & 16,17 & 0,50 & 0,38 & 1,58 \\
\hline Astronium fraxinifolium & 1 & 2 & 16,17 & 0,50 & 0,29 & 1,49 \\
\hline Helicteres lhotzkyana & 1 & 2 & 16,17 & 0,50 & 0,21 & 1,41 \\
\hline Randia armata & 1 & 2 & 16,17 & 0,50 & 0,20 & 1,40 \\
\hline Casearia decandra & 1 & 2 & 16,17 & 0,50 & 0,15 & 1,35 \\
\hline Tabebuia heptaphylla & 1 & 2 & 16,17 & 0,50 & 0,14 & 1,34 \\
\hline Piptadenia stipulacea & 1 & 2 & 16,17 & 0,50 & 0,13 & 1,33 \\
\hline Myrtaceae 1 & 1 & 2 & 16,17 & 0,50 & 0,09 & 1,29 \\
\hline Neea supubescens & 1 & 2 & 16,17 & 0,50 & 0,08 & 1,28 \\
\hline Coccoloba sp. & 1 & 2 & 16,17 & 0,50 & 0,04 & 1,24 \\
\hline Acacia paniculata & 1 & 2 & 16,17 & 0,50 & 0,03 & 1,23 \\
\hline Diplokelea floribunda & 1 & 2 & 16,17 & 0,50 & 0,03 & 1,23 \\
\hline Bauhinia leptantha & 1 & 2 & 16,17 & 0,50 & 0,03 & 1,23 \\
\hline
\end{tabular}


Tabela 5. Espécies amostradas no remanescente Fronteira, em Floresta Estacional Decidual de Terras Baixas, próximo à fronteira com a Bolívia, Corumbá, MS, e seus parâmetros fitossociológicos, em ordem decrescente de valor de importância (VI). N = número de indivíduos amostrados; $\mathrm{FA}=$ freqüência absoluta $(\%) ; \mathrm{DA}=$ densidade absoluta (indivíduos.ha ${ }^{-1}$ ); $\mathrm{DR}=$ densidade relativa $(\%) ;$ DoR = dominância relativa $(\%)$.

Table 5. Sampled species of Border remnants, in lowland deciduous forest, by Bolivia border, Corumba, MS, and its phytosociologics parameters, in decreasing order of importance value (VI). $\mathrm{N}=$ number of sampled individuals; FA = absolute frequency $(\%) ; \mathrm{DA}=$ Absolute density (individuous.ha $\left.{ }^{-1}\right) ; \mathrm{DR}=$ relative density $(\%)$; DoR = relative dominance $(\%)$.

\begin{tabular}{lrrrrrr}
\hline Espécie & N & FA & DA & DR & DoR & VI \\
\hline Sebastiania discolor & 27 & 65 & 999,00 & 33,75 & 17,27 & 72,34 \\
Phyllostylon rhamnoides & 8 & 35 & 296,00 & 10,00 & 37,98 & 59,45 \\
Zizyphus oblongifolius & 1 & 5 & 37,00 & 1,25 & 16,14 & 19,03 \\
cf. Savia sp. & 6 & 20 & 222,00 & 7,50 & 2,27 & 16,33 \\
Fabaceae 1 & 3 & 15 & 111,00 & 3,75 & 7,21 & 15,88 \\
Tabebuia heptaphylla & 6 & 20 & 222,00 & 7,50 & 1,25 & 15,31 \\
Maclura tinctoria & 3 & 15 & 111,00 & 3,75 & 2,65 & 11,32 \\
Helietta puberula & 3 & 15 & 111,00 & 3,75 & 1,34 & 10,00 \\
Celtis pubescens & 3 & 15 & 111,00 & 3,75 & 0,81 & 9,47 \\
Capparis retusa & 2 & 10 & 74,00 & 2,50 & 2,75 & 8,53 \\
Diplokeleba floribunda & 1 & 5 & 37,00 & 1,25 & 5,49 & 8,38 \\
Acosmium cardenasii & 2 & 10 & 74,00 & 2,50 & 1,59 & 7,37 \\
Randia armata & 2 & 10 & 74,00 & 2,50 & 0,27 & 6,05 \\
Allophyllus pauciflorus & 2 & 10 & 74,00 & 2,50 & 0,26 & 6,04 \\
Calycophyllum multiflorum & 1 & 5 & 37,00 & 1,25 & 0,45 & 3,34 \\
Myrtaceae 2 & 1 & 5 & 37,00 & 1,25 & 0,45 & 3,34 \\
Allophyllus edulis & 1 & 5 & 37,00 & 1,25 & 0,44 & 3,33 \\
Aporocactus flagelliformis & 1 & 5 & 37,00 & 1,25 & 0,41 & 3,30 \\
Rollinia emarginata & 1 & 5 & 37,00 & 1,25 & 0,22 & 3,11 \\
Coutarea hexandra & 1 & 5 & 37,00 & 1,25 & 0,20 & 3,09 \\
Coccoloba sp. & 1 & 5 & 37,00 & 1,25 & 0,15 & 3,04 \\
Caseria decandra & 1 & 5 & 37,00 & 1,25 & 0,12 & 3,01 \\
Bahunia rufa & 1 & 5 & 37,00 & 1,25 & 0,10 & 2,99 \\
Aspidosperma pyrifolium & 1 & 5 & 37,00 & 1,25 & 0,09 & 2,98 \\
Aspidosperma parvifolium & 1 & 5 & 37,00 & 1,25 & 0,09 & 2,98 \\
\hline
\end{tabular}

amostragem, ou seja, a área amostrada é estimada a partir da distância média entre os indivíduos. Numa floresta em que as distâncias entre os indivíduos são pequenas e as espécies apresentam uma distribuição espacial tendendo a uniforme, a amostragem de poucos indivíduos por espécie, superestima as densidades daquelas espécies menos freqüentes (Brower \& Zar 1984). Os valores foram superestimados na mata da Fronteira para as espécies amostradas com poucos indivíduos, por causa da menor amostragem (20 pontos). No entanto, apesar da mata do Taquaral apresentar distribuição espacial semelhante (tendendo a uniforme), com distância média entre árvores similar a da mata da Fronteira, os valores de densidade absoluta não foram superestimados porque a amostragem maior, com 50 pontos minimizou o efeito do método de quadrantes. Nas demais florestas decíduas (Aluvial e Submontana), os 20 pontos amostrados foram suficientes para evidenciar as espécies que ocorreram com maior dominância nessas matas. Esses resultados estão de acordo com o observado por Araújo et al. (1997), que as comunidades decíduas situadas em solos rasos com alta fertilidade natural, apresentam menor riqueza e diversidade e a ocorrência de espécies com alta dominância.

Assim, para as florestas decíduas com alta densidade de indivíduos e distância uniforme entre as árvores, aconselha-se uma amostragem por quadrantes de pelo menos 50 pontos, para uma estimativa mais confiável da densidade absoluta e para um levantamento florístico mais completo. $\mathrm{O}$ aumento do número de pontos em florestas decíduas com distribuição espacial das árvores ao acaso (não uniforme) também possibilitará 
Tabela 6. Índices de similaridade de Jaccard e de Czekanowski (números entre parênteses) para a vegetação arbórea dos remanescentes de Floresta Estacional Decidual em Corumbá, MS.

Table 6. Jaccard and Czekanowski (in parenthesis) similarities indexes to wood vegetation of deciduous forest remnants in Corumbá, MS.

\begin{tabular}{lcccc}
\hline & $\begin{array}{c}\text { Terras baixas } \\
\text { Taquaral }\end{array}$ & $\begin{array}{c}\text { Terras baixas } \\
\text { Fronteira }\end{array}$ & $\begin{array}{c}\text { Aluvial } \\
\text { Jacadigo }\end{array}$ & $\begin{array}{c}\text { Submontana } \\
\text { Jacadigo }\end{array}$ \\
\hline Terras Baixas Taquaral & - & $(53,75)$ & $(15,00)$ & $(22,50)$ \\
Terras Baixas Fronteira & 29,27 & - & $(12,50)$ & $(22,50)$ \\
Aluvial Jacadigo & 17,65 & 14,00 & - & $(16,25)$ \\
Submontana Jacadigo & 23,81 & 19,51 & 14,29 & - \\
\hline
\end{tabular}

a inclusão de espécies que ocorrem com menor freqüência, sem, no entanto, alterar as espécies dominantes levantadas com os 20 pontos iniciais, devido à alta dominância observada neste tipo de formação (Araújo et al. 1997).

As densidades totais de árvores estimadas para as quatro florestas estão dentro do intervalo de confiança de $95 \%$ (tabela 7) e o erro padrão foi um pouco maior nas florestas decíduas de Terras Baixas quando amostradas com apenas 20 pontos de quadrantes.

Considerando as densidades totais das árvores, o resultado no remanescente da Fronteira foi semelhante à mata do assentamento Taquaral; ambos apresentaram densidade total mais elevada que as demais áreas (tabela 7), com muitos indivíduos de menor porte e perfilhados, como Sebastiania discolor (Spreng.) Müll. Arg. Já os fragmentos florestais Aluvial e Submontana Jacadigo apresentaram uma densidade de árvores menor, com mais de indivíduos de grande porte, pertencentes a Acosmium cardenasii H.S. Irwin \& Arroyo e Aspidosperma australe Müll. Arg., respectivamente.
Esta variação no porte e na densidade total das árvores pode estar relacionada às distintas características de relevo e textura do solo (Spera et al. 1997), que afetam de forma diferenciada o escoamento, a penetração e o armazenamento de água no solo. As florestas de Terras Baixas estariam mais sujeitas ao encharcamento do solo no período chuvoso que os remanescentes de Floresta Aluvial e Submontana que apresentam um relevo favorável à drenagem. Sampaio et al. (1981) observaram, em áreas de caatingas, que a profundidade e a permeabilidade do solo, juntas, explicaram significativamente parte da variação encontrada na altura e densidade das plantas em vários locais estudados.

Das 67 espécies identificadas até o nível específico nas matas decíduas, a maioria também ocorre em outras formações, principalmente no chaco (27 espécies) e na caatinga (12 espécies), segundo consulta aos trabalhos de Ratter et al. (1988), Prado \& Gibbs (1993) e Pott \& Pott (1994). Outras espécies (9\%) ocorrem em savanas e florestas da Bolívia (Killen et al. 1993). Cerca de

Tabela 7. Número de espécies, distância média entre indivíduos, densidade total, intervalo de confiança e erro padrão para os remanescentes de Floresta Estacional Decidual em Corumbá, MS. Entre parênteses, os valores obtidos para os 20 pontos utilizados nas comparações de estrutura e florística.

Table 7. Number of species, average distance among individuals, total density, confidence interval and standard error to deciduous forest remnants in Corumba, MS. Values obtained in 20 sample points used in structure and floristic comparisons are given in brackets.

\begin{tabular}{lccccc}
\hline Remanescentes & Número de espécies & $\begin{array}{c}\text { Distância média } \\
(\mathrm{m})\end{array}$ & $\begin{array}{c}\text { Densidade total } \\
\left(\text { (indivíduo.ha }^{-1}\right)\end{array}$ & $\begin{array}{c}\text { Intervalo de confiança } \\
(95 \%)\end{array}$ & Erro padrão \\
\hline Terras Baixas Taquaral & 47 & 1,72 & 3.240 & $2.810 \mathrm{a} 3.710$ & 16,3 \\
& $(28)$ & $(1,78)$ & $(2.860)$ & $(2.290 \mathrm{a} 3.550)$ & $(36,2)$ \\
Terras Baixas Fronteira & 25 & 1,62 & 2.960 & $2.370 \mathrm{a} 3680$ & 37,5 \\
Aluvial Jacadigo & 32 & 3,02 & 1.020 & $814 \mathrm{a} 1270$ & 12,9 \\
Submontana Jacadigo & 24 & 2,50 & 1.350 & $1.080 \mathrm{a} 1680$ & 17,1 \\
\hline
\end{tabular}


$39 \%$ das espécies amostradas são de ampla ocorrência (Pott \& Pott 1994, Lorenzi 1992) e mesmo entre essas, sete são mencionadas por Ratter et al. (1988), Prado \& Gibbs (1993) e Pott \& Pott (1994) como frequientes na caatinga (Aspidosperma subincanum Mart., Coutarea hexandra (Jacq.) K. Schum., Celtis pubescens Spreng. e Maclura tinctoria (L.) D. Don ex Steud.) ou no chaco (Acacia paniculata Willd., Pterogyne nitens Tul. e Tabebuia heptaphylla (Vell.) Toledo. Estes resultados confirmam o observado por Prado \& Gibbs (1993), que mencionam a vegetação decídua de Corumbá como integrante das formações residuais de climas secos do Pleistoceno, da qual também fazem parte a Caatinga Nordestina e uma faixa entre Santa Cruz, na Bolívia, e Corrientes, na Argentina.

No presente estudo foram encontrados novos registros de espécies para a região, como Sebastiania discolor (Spreng.) Müll. Arg. e Erythroxylum patentissimum O.E. Schulz que foram observados nos remanescentes de mata decídua de Terras Baixas e Achatocarpus praecox Griseb., na mata Aluvial do Jacadigo. Estas espécies são comuns nas áreas de chaco do Paraguai e da Argentina, mas somente agora foram coletadas e registradas para a região de Corumbá e para o estado de Mato Grosso do Sul. Isto evidencia a necessidade de coletas e de estudos, tanto do ponto de vista botânico como ecológico, devido á escassez de informações em literatura e também pela sua estrutura e composição florística peculiar, com muitos elementos da caatinga e do chaco.

Sugere-se a criação urgente de áreas de conservação nas três formações estacionais deciduais (Aluvial, Terras Baixas e Submontanas) da região, em especial nas Florestas de Terras Baixas que estão mais fortemente ameaçadas pela urbanização e pela implantação de assentamentos por se localizarem em relevo plano.

Agradecimentos - Ao laboratorista Antonio, pela sua dedicação no preparo das exsicatas; aos colegas de apoio, Oslain, Denis, Moacir, Haroldo e Waldomiro que, com boa vontade, nos auxiliaram nas idas ao campo; à Rosilene, do laboratório de sensoriamento remoto, pela estimativa das áreas dos remanescentes e auxílio na confecção da figura; à Rosilene R. Silva, bolsista de iniciação RHAE-CNPq, pela digitação dos dados; ao colega e pesquisador Guilherme M. Mourão, pelas sugestões ao manuscrito; aos botânicos dos herbários de Corrientes (CTES), A. Schinini (Achatocarpaceae), C.L. Cristóbal (Sterculiaceae) e M. S. Ferruci (Sapindaceae), Edimburgo (E), J.A. Ratter (Apocynaceae, Boraginaceae, Fabaceae, Mimosaceae e Sapotaceae), HUEFS, E. Mello (Polygonaceae), ICN, M. Sobral
(Myrtaceae), Museu Botânico Municipal de Curitiba (MBM), G. Hatschbach (Rutaceae) e Universidade Estadual de Campinas (UEC), J. Semir (Bombacaceae), por identificações.

\section{Referências bibliográficas}

ANGIOSPERM PHYLOGENY GROUP. 2003. An update of the angiosperm phylogeny group classification for the orders and families of flowering plants: APG II. Botanical Journal of the Linnean Society 141:399-436.

ARAÚJO, G.M., RODRIGUES, L.A. \& IVIZI,L. 1997. Estrutura fitossociológica e fenologia de espécies lenhosas de mata decídua em Uberlândia, MG. In Contribuição ao conhecimento ecológico do Cerrado. Anais do III Congresso de Ecologia do Brasil (L.L. Leite \& C.H. Saito, orgs.). Departamento de Ecologia, Universidade de Brasília, Brasília, p.22-28.

BRASIL. 1982. Projeto Radambrasil. Folha SE.21 Corumbá e parte da folha SE.20: geologia, geomorfologia, pedologia, vegetação e uso potencial da terra. Levantamento de Recursos Naturais, 27, Ministério das Minas e Energia. Departamento Nacional de Produção Mineral, Rio de Janeiro.

BROWER, J.E. \& ZAR, J.H. 1984. Field and laboratory methods for general ecology. $2^{\text {nd }}, C$. Brown, Iowa.

CARVALHO, D.A., OLIVEIRA FILHO, A.T. \& VILELA, E.A. 1999. Florística e fitossociologia da vegetação arbóreoarbustiva de floresta ripária decídua do baixo Paranaíba (Santa Vitória, Minas Gerais). Revista Árvore 23:311-320.

EMBRAPA. 1999. Sistema brasileiro de classificação de solos. Empresa Brasileira de Pesquisa Agropecuária, Embrapa Solos/Embrapa Produção de Informação, Rio de Janeiro Brasília.

HOEHNE, F.C. 1923. Phytophysionomia do Estado de MattoGrosso e ligeiras notas a respeito da composição e distribuição da sua flora: estudo preliminar. Editora Nacional, São Paulo.

IBGE. 1992. Manual técnico da vegetação brasileira. Fundação Instituto Brasileiro de Geografia e Estatística, Departamento de Recursos Naturais e Estudos Ambientais, Rio de Janeiro.

JURACY, A.R.M., SALIS, S.M. \& DAMASCENO JÚNIOR, G.A. 1999. Avaliação florística do Morro Bocaina, Corumbá, MS. In Anais do II Simpósio sobre Recursos Naturais e Sócio-econômicos do Pantanal (M. Dantas, J.B. Catto \& E.K. Resende, coords.). Embrapa Pantanal, Corumbá, p.327-332.

KILLEEN, T.J., GARCÍA, E.E. \& BECK, S.G. 1993. Guía de arboles de Bolivia. Herbario Nacional de Bolivia/Missouri Botanical Garden, St. Louis/La Paz.

KREBS, C.J. 1989. Ecological Methodology. Harper \& Row, New York.

KREBS. 1998. Krebs Ecological Methodology for Windows. Charles J. Krebs. Versão 0.93 no ar desde 21 de fevereiro 1998. Disponível em <http://www.biology.ualberta.ca/ jbrzusto/krebswin.html>. (acesso em 28/05/2004). 
LORENZI, H. 1992. Árvores brasileiras: manual de identificação e cultivo de plantas arbóreas nativas do Brasil. Plantarum, Nova Odessa.

LORENZI, H. 1998. Árvores brasileiras: manual de identificação e cultivo de plantas arbóreas nativas do Brasil. v.2. Plantarum, Nova Odessa.

MALME, G.O.A.N. 1905a. Die Bauhinien von Matto Grosso. Arkiv för Botanik 5:1-16.

MALME, G.O.A.N. 1905b. Die Vochysiaceen Matto Grosso. Arkiv för Botanik 5:1-12.

MALME, G.O.A.N. 1931. Die Leguminosen der zweitn Regnellschen Reise. Arkiv för Botanik 23:1-99.

MARTINS, F.R. 1991. Estrutura de uma floresta mesófila. Série Teses, Editora da Universidade Estadual de Campinas, Campinas.

MATO GROSSO DO SUL. 1989. Fundação Instituto de Apoio ao Planejamento do Estado - FIPLAN. Recursos Naturais - Vegetação. Secretaria de Planejamento e Coordenação Geral, Campo Grande.

MENDONÇA, R.C., FELFILI, J.M., WALTER, B.M.T., SILVA JÚNIOR, M.C., REZENDE, A.V., FILGUEIRAS, T.S. \& NOGUEIRA, P.E. 1998. Flora vascular do Cerrado. In Cerrado: ambiente e flora (S.M. Sano \& S.P. Almeida, eds.). Embrapa-CPAC, Planaltina, p.289-539.

MISSOURI BOTANICAL GARDEN. 2002. Missouri Botanical Garden W3 Tropicos. Vascular Tropicos Nomenclatural Database no ar desde 1995. Disponível em <http:// www.mobot.org/W3T/Search/vast.html >. (acesso em 14/07/2003).

MOORE, S.M. 1895. The phanerogamic botany of the Mato Grosso expedition 1891-1892. Transactions of the Linnean Society of London. Series Botany 4:265-516.

OLIVEIRA FILHO, A.T. 1998. Effects of canopy gaps, topography, and soils on the distribution of woody species in a Central Brazilian deciduous dry forest. Biotropica 30:362-375.

PIELOU, E.C. 1984. The interpretation of ecological data. John Wiley \& Sons, New York.

PINARD, M.A. \& HUFFMAN, J. 1997. Fire resistance and bark properties of tree in a seasonally dry forest in eastern Bolivia. Journal Tropical Ecology 13:727-740.

POTT, A. \& POTT, V.J. 1986. Plantas colonizadoras da Estrada Transpantaneira (da fazenda Leque ao Retiro Chatelodo) na Nhecolândia, Pantanal. Comunicado Técnico 7. Embrapa-CPAP, Corumbá.

POTT, A. \& POTT, V.J. 1994. Plantas do Pantanal. EmbrapaCPAP/Embrapa-SPI, Corumbá/Brasília.

POTT, A., SILVA, J.S.V., ABDON, M.M., POTT, V.J., RODRIGUES, L.M., SALIS, S.M. \& HATSCHBACH, G.G. 1997. Vegetação. In Brasil. Ministério do Meio Ambiente, dos Recursos Hídricos e da Amazônia Legal. Plano de conservação da Bacia do Alto Paraguai (Pantanal) PCBAP. Diagnóstico dos meios físico e biótico. MMA/ SEMAM/ PNMA, Brasília, v.2, p.3-179.
POTT, A., SILVA, J.S.V., SALIS, S.M., POTT, V.J. \& SILVA, M.P. 2000. Vegetação e uso da terra. In Zoneamento ambiental da Borda Oeste do Pantanal: Maciço do Urucum e adjacências (J.S.V. Silva, org.). Embrapa Comunicação e Transferência de Tecnologia, Brasília, p.111-131.

PRADO, D.E. \& GIBBS, P.E. 1993. Patterns of species distributions in the dry seasonal forest South America. Annals of the Missouri Botanic Garden 80:902-927.

PRADO, D.E., GIBBS, P.E., POTT, A. \& POTT, V.J. 1992. The chaco-transition in southern Mato-Grosso, Brazil. In Nature and dynamics of forest-savanna boundaries (P.A. Furley, J. Proctor \& J.A. Ratter, eds.). Chapman \& Hall, London, p.451-470.

RAMELLA, L. \& SPICHIGER, R. 1989. Interpretación preliminar del medio físico y de la vegatación del Chaco Boreal - Contribución al estudio de la flora y de la vegetación del Chaco. I. Candollea 44:639-680.

RATTER, J.A., POTT, A., POTT, V.J., CUNHA, C.N. \& HARIDASSAN, M. 1988. Observations on woody vegetation types in the Pantanal and around Corumbá. Notes from the Royal Botanic Garden Edinburgh 45:503-525.

SALES, M.F., MAYO, S.J. \& RODAL, M.J.N. 1998. Plantas vasculares das florestas serranas de Pernambuco: um checklist da flora ameaçada dos brejos de altitude. Imprensa Universitária - UFRPE, Recife.

SALIS, S.M., POTT, V.J. \& POTT, A. 1999. Fitossociologia de formações arbóreas da Bacia do Alto Paraguai. In Anais do II Simpósio sobre recursos naturais e sócioeconômicos do Pantanal (M. Dantas, J.B. Catto \& E.K. Resende, coords.). Embrapa Pantanal, Corumbá, p.357-374.

SAMPAIO, E.V.S.B., ANDRADE-LIMA, D. \& GOMES, M.A.F. 1981. O gradiente vegetacional das caatingas e áreas anexas. Revista Brasileira de Botânica 4:27-30.

SCHEINVAR, L. 1985. Cactáceas. In Flora Ilustrada Catarinense (R. Reitz, ed.). Herbário Barbosa Rodrigues, Itajaí.

SHEPHERD, G.J. 1988. FITOPAC 1. Manual do usuário. Departamento de Botânica, Instituto de Biologia, Universidade Estadual de Campinas. Campinas.

SORIANO, B.M.A. 1997. Caracterização climática de Corumbá, MS. Boletim de Pesquisa, 11. Embrapa-CPAP, Corumbá.

SPERA, S.T., TOSTO, S.G., CARDOSO, E.L. \& OLIVEIRA, H. 1997. Levantamento de reconhecimento de alta intensidade dos solos e avaliação da aptidão agrícola das terras da borda oeste do Pantanal: Maciço do Urucum e adjacências, MS. Boletim de Pesquisa 9, EmbrapaCPAP/Embrapa-CNPS, Corumbá/Rio de Janeiro.

VALVERDE, O. 1972. Fundamentos geográficos do planejamento rural do município de Corumbá. Revista Brasileira de Geografia 34:49-144.

WERNECK, M.S., FRANCESCHINELLI, E.V. \& TAMEIRÃO NETO, E. 2000. Mudanças naflorística e estrutura de uma floresta decídua durante um período de quatro anos (1994-1998), na região do Triângulo mineiro, MG. Revista Brasileira de Botânica 23:399-411. 